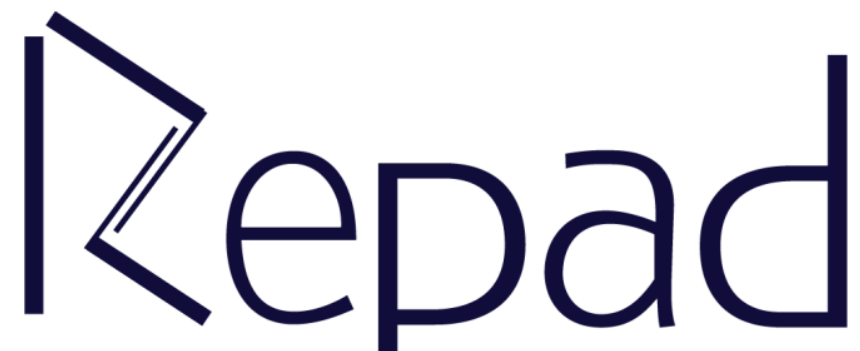

Vol. 1, N. 1 Dezembro/2017

Revista Estudos e

Pesquisas em Administração

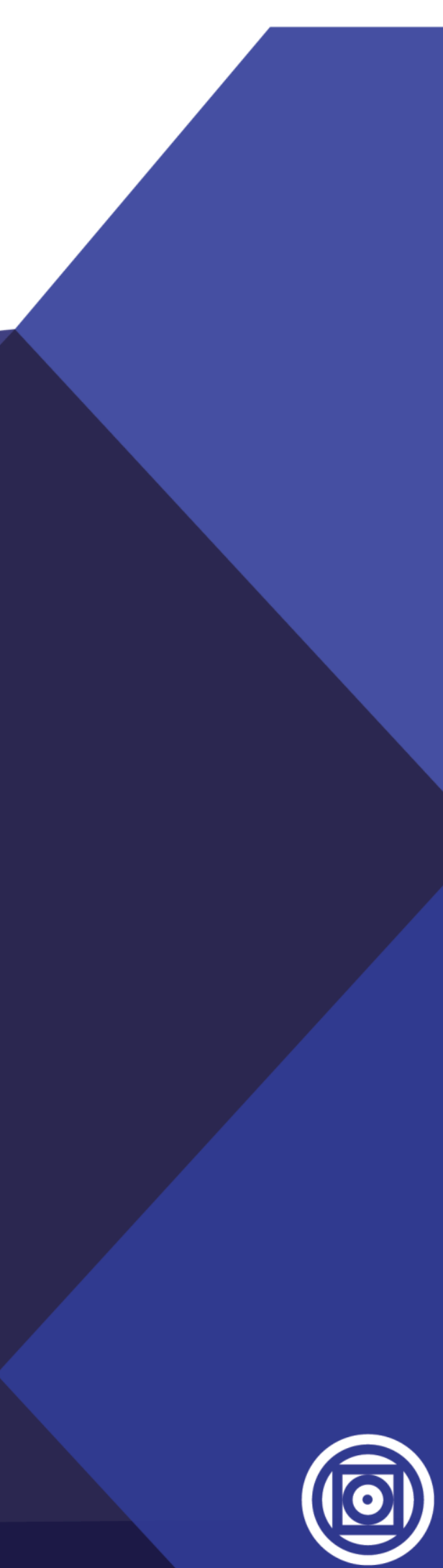




\title{
MUDANÇAS EM DESEJOS E OPORTUNIDADES NO STATUS DE PECUARISTA PANTANEIRO
}

André Ribeiro Lacerda

Universidade Federal de Mato Grosso

\begin{abstract}
RESUMO
O problema de pesquisa aqui enfrentado foi inspirado na teoria da escolha racional e pode ser enunciado nos seguintes termos: por que parte significativa da nova geração de pecuaristas do pantanal de Poconé não vê mais a pecuária como uma atividade econômica atrativa que vale a pena investir enquanto status ocupacional? Duas hipóteses foram formuladas para respondê-lo: (1) Mudanças na dimensão das oportunidades: o conjunto de status que desenha a estrutura organizacional da ocupação não é mais atrativo para pretensos pecuaristas; (2) Mudanças na dimensão de desejos: aqueles que escolhem o status de pecuarista pantaneiro o fazem enquanto atividade econômica complementar, secundária e que minimize conflitos com o papel social de status ocupacional principal. Entrevistas realizadas com 29 pecuaristas entre 2014 e 2015 sustentam as duas hipóteses.
\end{abstract}

Palavras-Chave: Escolha Racional; Status Ocupacional; Pantanal.

Pesquisa financiada pelo MCT/CPP.

\section{CHANGES IN WISHES AND OPPORTUNITIES ON THE STATUS OF PANTANALIAN CATTLEMAN}

\begin{abstract}
The research problem dealt with in this work was inspired by the theory of rational choice and can be enunciated in the following terms: why does a significant portion of the new generation of Poconé Pantanal cattlemen no longer view livestock farming as an attractive economic activity worth investing in as an occupational status? Two hypotheses were formulated to answer this question: (1) Changes in the dimension of the opportunities: the status set that outlines the organizational structure of the occupation is no longer attractive to potential cattlemen; (2) Changes in the dimension of wishes: those who choose the status of Pantanalian cattlemen do so taking up that occupation as a side economic activity, a secondary activity that minimizes conflicts with the social role of the main occupational status. Interviews carried out with 29 cattlemen between 2014 and 2015 support both hypotheses.
\end{abstract}

Keywords: Rational Choice; Occupational Status; Pantanal

Research funded by MCT/CPP. 


\section{INTRODUÇÃO}

As ocupações e profissões podem ser entendidas como estruturas organizacionais no sentido abordado pela sociologia das organizações (ETZIONI, 1979) e pela sociologia das profissões (GORMAN; SANDEFUR, 2011). E enquanto status social, as ocupações e profissões têm uma posição na hierarquia do mercado profissional e, portanto, podem ser avaliadas como tendo mais ou menos prestígio social.

A literatura sociológica clássica e contemporânea apresenta diversas evidências de mudanças sociais na escolha de status sociais que deixaram de ser majoritariamente atribuídos e passaram a ser fundamentalmente adquiridos. Mudanças sociais como aquelas que envolvem status ocupacionais e que também podem ser entendidas como transformações em desejos e oportunidades, conforme Elster (1994; 2010).

A ação humana pode ser vista como o resultado da operação de dois filtros sucessivos. O primeiro diz respeito ao conjunto de todas as ações que um indivíduo poderia empreender e envolve as coerções físicas, econômicas, legais e psicológicas que o ator social enfrenta. As ações que são consistentes com essas coerções constituem seu conjunto de oportunidades. Enquanto o segundo filtro refere-se ao mecanismo que determina qual a ação do conjunto de oportunidades será executada (ELSTER, 1994; 2010).

A hipótese geral desse trabalho defende que as mudanças que fazem com que um status social, nesse caso um status ocupacional, passe de majoritariamente atribuído para fundamentalmente adquirido, envolvem mudanças em desejos e oportunidades.

Ser um pecuarista no pantanal de Mato Grosso envolve o desafio extra de administrar algo que inexiste no horizonte do pecuarista de terra firme: o ciclo das águas. $\mathrm{Na}$ enchente e grande parte da vazante o pecuarista deve retirar o gado para lugares mais altos, se a sua propriedade tem cordilheiras isto é facilitado, mas caso não tenha áreas que não são atingidas pelo período da cheia no pantanal, ele deve alugar outra propriedade e levar seu gado para lá. Isto constitui um custo extra, pois o período de enchentes aumenta a perda de cabeça de gado e diminui a vida útil das cercas, que terão que ser reconstruídas.

Em um tempo em que as propriedades eram extensas e o rebanho era numeroso, estes custos eram compensados por outras vantagens e ser um pecuarista pantaneiro era um status fundamentalmente atribuído, pois ele era herdado da família, geralmente do pai. Mas as coisas mudaram e muitas destas vantagens desapareceram.

O problema de pesquisa aqui enfrentado pode ser enunciado nos seguintes termos: por que parte significativa da nova geração de pecuaristas do pantanal de Poconé não vê mais a pecuária como uma atividade econômica atrativa que vale a pena investir enquanto status ocupacional?

O objetivo deste trabalho é apresentar as mudanças identificadas na estrutura do status de pecuaristas pantaneiros de Poconé - MT como um exemplo de escolha racional (ELSTER, 1994, 2010; HECHTER; KANAZAWA, 1999; SANDERSON, 2001). A hipótese principal defende que as mudanças identificadas na estrutura do status de pecuarista envolvem mudanças em desejos e oportunidades e que, colocado desta maneira, as mudanças nos ajudam a entender porque a nova geração de pecuaristas pantaneiros vê a pecuária no pantanal como uma atividade econômica complementar e por que a maioria de seus filhos não se interessa por ela.

Visto como variável dependente, o status de pecuarista pantaneiro tem experimentado transformações como outros status sociais do conjunto de status a que pertence o pecuarista pantaneiro. Inspirado na teoria da escolha racional formulou-se duas hipóteses para explicar as 
mudanças identificadas: (1) As mudanças na estrutura social que se desenham a partir do status de pecuarista pantaneiro (conjunto de status) não favorecem o investimento no status ocupacional de pecuarista pantaneiro - mudanças nas oportunidades; (2) Aqueles que escolhem o papel social de pecuarista pantaneiro o fazem enquanto atividade econômica complementar, secundária e que minimizem conflito com o papel de seu status ocupacional principal mudanças nos desejos.

Este artigo está organizado em mais três seções, além desta. A segunda seção aborda o referencial teórico da pesquisa, os conceitos em torno dos quais se problematizou e formulouse as hipóteses aqui defendidas. A terceira apresenta os procedimentos metodológicos que informa que tipo de dado foi coletado e como foi coletado e, finalmente, a quarta seção em que se discute os resultados, limitações e algumas questões para futuras pesquisas.

\section{REFERENCIAL TEÓRICO}

Da perspectiva da teoria da escolha racional (ELSTER, 1994; 2010; HECHTER; KANAZAWA, 1999; SANDERSON, 2001), a questão da escolha do status ocupacional nas sociedades industrializadas avançadas é importante do ponto de vista sociológico e psicológico porque envolve a decisão de investir no status adquirido que estipulará teoricamente as disponibilidades de tempo e energia a ser investida nos outros statuses, atribuídos e adquiridos. Conforme Hopcroft e Whitmeyer (2010) sustentam, nas sociedades industrializadas avançadas, o investimento em status ocupacionais envolve longos anos de socialização educacional e treinamento ocupacional.

As mudanças identificadas no status de pecuarista pantaneiro sugerem mudanças no processo social de escolha de uma ocupação que antes era um status social fundamentalmente atribuído e que agora, com a perda dos referenciais que o tornavam um processo vinculado à família, no pantanal de Poconé, ele deixa de ser um processo fundamentalmente com características de status atribuído e passa a ter características mais de status adquirido.

Não se tratar de negar a influência da família na escolha dos status ocupacionais de seus filhos, mas de explorar teórica e empiricamente o contraste que existe em relação às várias outras áreas ocupacionais em que o trabalho não é mais uma atividade herdada, isto é, em que a transferência do controle do empreendimento ocorre entre membros da mesma família, como ainda ocorre na agricultura, conforme apontam Kiyota e Perondi (2014).

A questão da escolha do status ocupacional de pecuarista pantaneiro pode ser vista como um problema de escolha de investimento em que o ator social, filho de pecuaristas, tem três opções: ele pode continuar a tradição de família e escolher ser um pecuarista em tempo integral, ele escolhe ser um pecuarista em seu tempo livre, tendo outra ocupação, ou escolhe outra ocupação e não tem mais nenhum vínculo com a pecuária.

Nos moldes em que Elster (1994; 2010) enquadra a relação entre desejos e oportunidades, pode-se defender que as coerções físicas, legais, econômicas e psicológicas com que os indivíduos filhos de pecuaristas pantaneiros se depararam eram muito diferentes do que é encontrado hoje. A influência da família era muito mais forte já que sua estrutura estava desenhada em torno da figura paterna e, no caso dos pecuaristas pantaneiros, a pecuária era uma atividade econômica centrada na família. Portanto, o status de pecuarista estava fortemente vinculado à família e, na família resolvia-se a sucessão ocupacional. Pode-se dizer, por isso, 
que para alguns filhos, provavelmente mais do que para outros, seu conjunto de oportunidades, no que se refere à escolha de seu status ocupacional, era restrito.

Quanto maior prestígio oferece um status ocupacional, mais atrativo ele se torna aos olhos daqueles que pretendem exercê-lo. Ser um pecuarista no pantanal de Poconé há 50 anos era exercer um status de prestígio que oferecia algumas recompensas vantajosas. Muitos pecuaristas exerciam cargos públicos eletivos ou não, e isso constitui uma evidência do prestígio da ocupação. Portanto, nesse sentido, era uma ocupação atrativa, na perspectiva dos desejos (ELSTER, 1994; 2010).

A situação em que um status ocupacional deixa de ser atribuído e de que os atores sociais deixam de invocar a tradição familiar como razão para sua escolha parece ser uma situação limite entre: (1) escolher entre o status atribuído e o adquirido, entre a busca pelo status como algo racional para se obter poder e a busca de status como um fim em si mesmo; (2) a relação entre desejos e oportunidade, pois as situações sociais dos filhos que escolhiam a pecuária são bem diferentes em um contexto em que havia poucos status ocupacionais enquanto possibilidade de escolha e o mundo poconeano de hoje em que ser pecuarista significa ter uma propriedade menor, menos prestígio e em que o leque de oportunidades ocupacionais é maior, em quantidade e viabilidade, visto que a capital do Estado ficou mais perto. Por tudo isso, podese dizer que tais questões permitem problematizar a influência que os statuses atribuídos do ator social têm sobre a escolha do status que ele adquire na estrutura ocupacional. Esta questão foi pioneiramente enquadrada por Blau e Duncan (1967).

Um dos grandes desafios da pesquisa foi encontrar os pecuaristas pantaneiros. Muitas fazendas localizadas no baixo pantanal só são acessíveis de avião. $O$ pantanal é uma área alagada em sua maior parte, com $250.000 \mathrm{~km}$ de extensão, altitude média de 100 metros, situado no sul do Estado de Mato Grosso e o noroeste do Estado de Mato Grosso do Sul no Brasil, além de estender para o Paraguai e Bolívia.

Em Mato Grosso, a área do pantanal, chamada de pantanal norte, abarca sete cidades: Cáceres, Poconé, Santo Antônio do Leverger, Barão Melgaço, Itiquira, Nossa Senhora do Livramento e Lambari D'Oeste (VILA DA SILVA; ABDON, 1998).

Por serem mais próximas da capital, Cuiabá, algumas dessas cidades desenvolvem relações mais estreitas em termos de fluxo de pessoas e comércio. É o caso de Poconé, cidade de 31.779 habitantes, localizada a 100 quilômetros de Cuiabá, capital do Estado de Mato Grosso.

Durante um tempo, o status de pecuaristas pantaneiro gozou de elevado prestígio na sociedade mato-grossense e na sociedade da cidade de Poconé. O pecuarista pantaneiro chegou a imprimir culturalmente um estilo de vida, denominado de pantaneiro. Este estilo combinava valores religiosos católicos, estratificação social baseada em grande desigualdade social em que o pecuarista ocupava o topo da hierarquia social, grandes propriedades rurais para criação de gado extensivo, nas quais viviam a família nuclear do pecuarista e a família de seus empregados, e baixa produtividade, pois o gado era criado solto e as tecnologias utilizadas eram pouco especializadas.

Esta estrutura social, aqui entendida como o conjunto de statuses sociais vinculados ao status de pecuarista pantaneiro e os sistemas de cultura aos quais ele está e estava ligado (MARTIN, 2009; TURNER, 2000) vem sofrendo transformações.

\section{PROCEDIMENTOS METODOLÓGICOS}


Este estudo coletou dados de uma subpopulação dos pecuaristas do pantanal de Poconé, a dos pecuaristas filiados ao sindicato dos produtores rurais do município. Embora não seja representativa do universo dos pecuaristas do pantanal poconeano, ela é representativa dos pecuaristas pantaneiros que têm relação com a cidade de Poconé e que são herdeiros do estilo de vida dos pecuaristas que fizeram da pecuária no pantanal uma atividade econômica e um modo de vida. Este pecuarista tinha parte de sua vida social anual vinculada à cidade de Poconé, onde também residia.

As dificuldades econômicas enfrentadas pelos pecuaristas pantaneiros e o maior rigor das fiscalizações das secretarias estaduais de meio ambiente e do trabalho, têm dificultado o trabalho de entrevistas, pois os pecuaristas tornaram-se arredios e desconfiados. Muitos tendem associar as pesquisas ao trabalho de fiscalização e, por isto, ou se negam a conceder entrevistas ou, quando concordam, se negam a informar algumas coisas, como por exemplo, o tamanho da propriedade e quantidade de cabeça de gado. Resistência que não parece incomum (SILVA; SILVA, 1995).

As entrevistas com questões fechadas e algumas questões abertas foram realizadas entre agosto de 2014 e março de 2015. Apesar da estruturação do questionário ter sido testada e retestada, algumas questões mantiveram-se abertas, pois ainda não havia conhecimento da abrangência e da variabilidade das possíveis respostas.

Em função das dificuldades de acesso ao pantanal, desenhou-se uma amostra pelas vias de acesso, como uma amostra por conglomerados. Quatro vias de acesso foram identificadas: Estrada Parque Transpantaneira; Estrada Poconé-Porto Cercado; Estrada do Boqueirão e Rodovia Poconé-Cuiabá. Por estas estradas se alcançam as estradas vicinais.

Segundo o posto do Instituto de Defesa Agropecuária do Estado de Mato Grosso (INDEA-MT) em Poconé, existem 2113 propriedades rurais no município, 1556 na terra firme e 557 no pantanal. O sindicato dos produtores rurais de Poconé representa apenas os pecuaristas pantaneiros. Os pecuaristas de terra firme não são associados. A direção do sindicato registra 130 associados, sendo que menos de trinta associados participam das atividades cotidianas do sindicato. Muitos dos pecuaristas que foram entrevistados declararam que não participam mais das reuniões e nem colaboram com a taxa mensal. Foram entrevistados 29 pecuaristas, ou seja, $22,30 \%$ da população de pecuaristas do sindicato.

Basicamente, após a tabulação dos dados, priorizou-se a análise de questões fechadas. Questões abertas foram agrupadas utilizando-se a técnica de categorização de análise de conteúdo.

\section{APRESENTAÇÃO E DISCUSSÃO DOS DADOS}

Dados relativos à hipótese 1 mostram mudanças no conjunto de oportunidades: as mudanças na estrutura social que se desenham a partir do status de pecuarista pantaneiro (conjunto de status) não favorecem o investimento no status ocupacional de pecuarista pantaneiro.

Para testar essa hipótese, foram realizadas três perguntas: (1) é possível viver exclusivamente da pecuária no pantanal hoje? (2) em que lugar o senhor reside? E (3) seus filhos ajudam na fazenda? As respostas para essas perguntas são apresentadas na Tabela $1 \mathrm{e}$ Gráficos 1 e 2. 
Tabela 1 - Vivem exclusivamente da pecuária

\begin{tabular}{|c|c|}
\hline Exclusivamente & Proporção \\
\hline Sim & $20,68 \%$ \\
\hline Não & $79,32 \%$ \\
\hline \multicolumn{2}{|c|}{ Fonte: A pesquisa (2017) }
\end{tabular}

Fonte: A pesquisa (2017)

Gráfico 1 - Em que lugar o senhor reside?

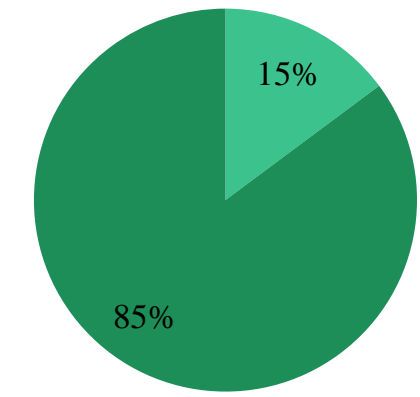

- Em outro município

- No município em que fica a fazenda

Fonte: A pesquisa (2017)
Gráfico 2 - Filhos ajudam na fazenda?

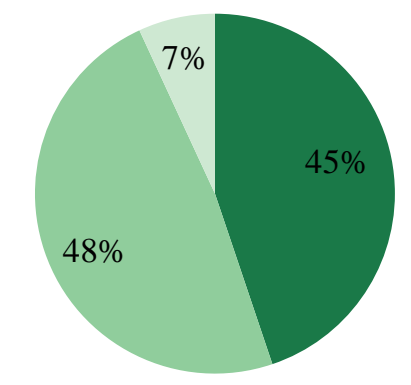

$\square$ Sim $\square$ Não $\square$ Às vezes

Fonte: A pesquisa (2017)

A estrutura de produção da pecuária pantaneira era basicamente familiar, baseada na grande propriedade e na pecuária extensiva. Neste cenário, a ajuda dos filhos era fundamental, que posteriormente assumiam a fazenda.

Os dados relativos à hipótese $\mathbf{2}$ mostram mudanças nos desejos: aqueles que escolhem o status de pecuarista pantaneiro o fazem enquanto atividade econômica complementar, secundária e que minimize conflitos com o papel de seus status ocupacional principal. Para testá-la, duas perguntas foram feitas:

$\checkmark$ Desenvolve outras atividades econômicas?

$\checkmark$ Qual das atividades econômicas é a principal, a pecuária ou a outra?

O Gráfico 3 mostra que 69\% desenvolve outras atividades econômicas. Entre aqueles que disseram não desenvolver outra atividade econômica, alguns sublinhavam que não desenvolviam naquele momento. Geralmente eram pecuaristas com mais de 60 anos que já tinham se aposentado de sua outra atividade. Para conhecer, entre aqueles que desenvolvem outras atividades econômicas, quais as principais atividades por eles desenvolvidas, perguntamos: qual a outra atividade econômica?

Podemos dizer que quatro pecuaristas da nova geração foram entrevistados, embora na fase de coleta de dados inicial e na fase de testes, outros quatro também concederam entrevistas. Eles se destacam por defender claramente que a pecuária no pantanal só é viável enquanto atividade econômica complementar, por defender uma pecuária mais empresarial e por criticarem a insistência da velha geração em acreditar que a pecuária pantaneira extensiva de outrora ainda seja viável.

Gráfico 3 - Desenvolve outras atividades econômicas? 


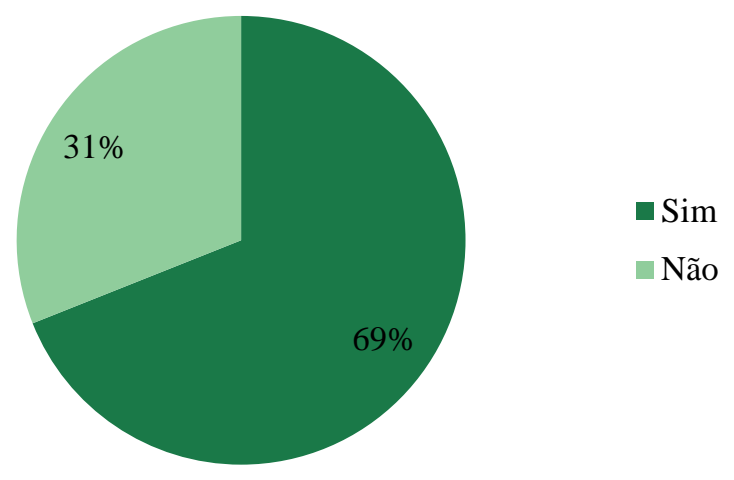

Fonte: A pesquisa (2017)

Quando perguntados sobre qual a atividade econômica desenvolvida é a atividade principal se a pecuária ou a outra, $65 \%$ afirmaram ser a outra atividade e $35 \%$ a pecuária. $\mathrm{O}$ Gráfico 4 apresenta os tipos de atividade exercidas.

Gráfico 4 - Tipos de atividade econômica exercida

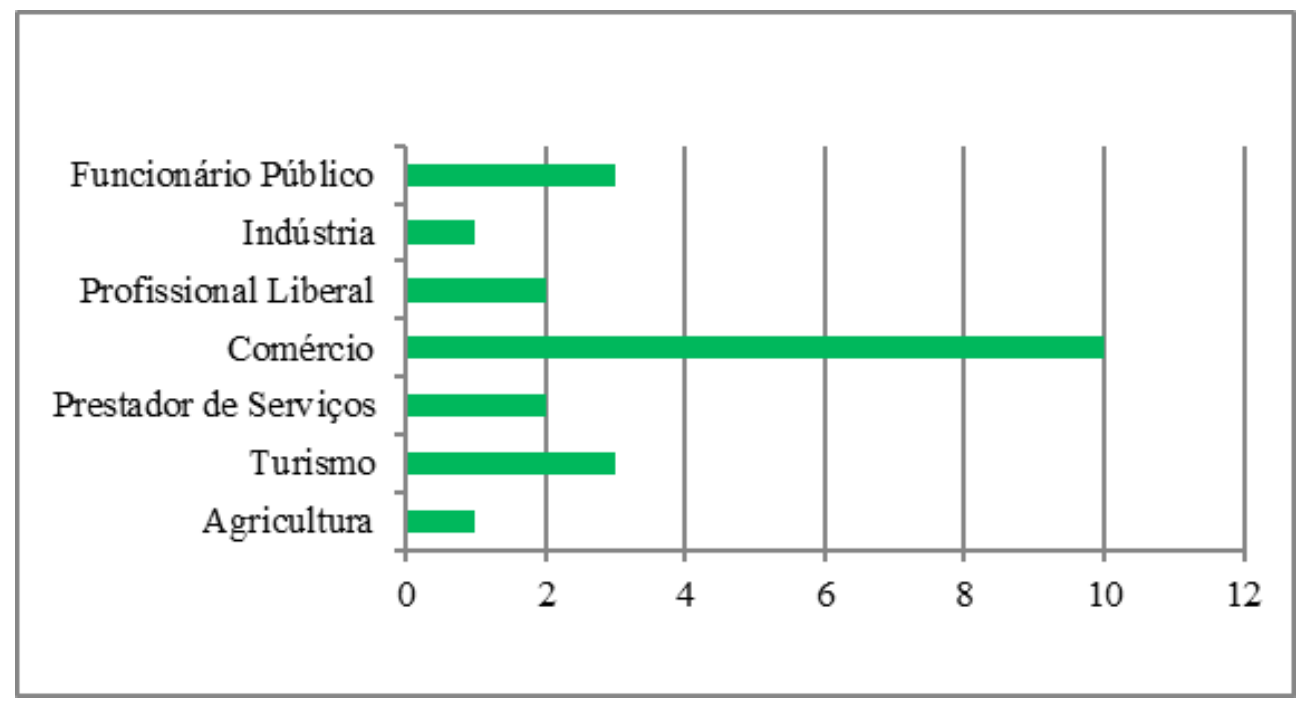

Fonte: A pesquisa (2017)

Para averiguar possíveis diferenças entre a geração mais velha e a mais nova, dados referentes à ocupação do pai, Tabela 2, e os motivos de ter se tornado pecuarista, Gráfico 5, foram coletados.

A idade não é a variável mais importante para distinguir os velhos da nova geração de pecuaristas. A nova geração pode ser caracterizada mais por desenvolver outra ocupação, por não acreditar mais que a pecuária pode ser desenvolvida com exclusividade e por tentar desenvolvê-la como complemento de outra ocupação. 
Tabela 2 - Ocupação do Pai

\begin{tabular}{|c|c|}
\hline Ocupação do Pai & Proporção \\
\hline Pecuarista & $68,96 \%$ \\
\hline Não Pecuarista & $31,03 \%$ \\
\hline
\end{tabular}

Fonte: A pesquisa (2017)

É importante ressaltar que entre aqueles que não têm pais pecuaristas, alguns se tornaram pecuaristas porque a esposa é filha de pecuaristas e herdou a terra. Os pecuaristas entrevistados em média afirmaram sem pesar que seus filhos não serão pecuaristas no pantanal.

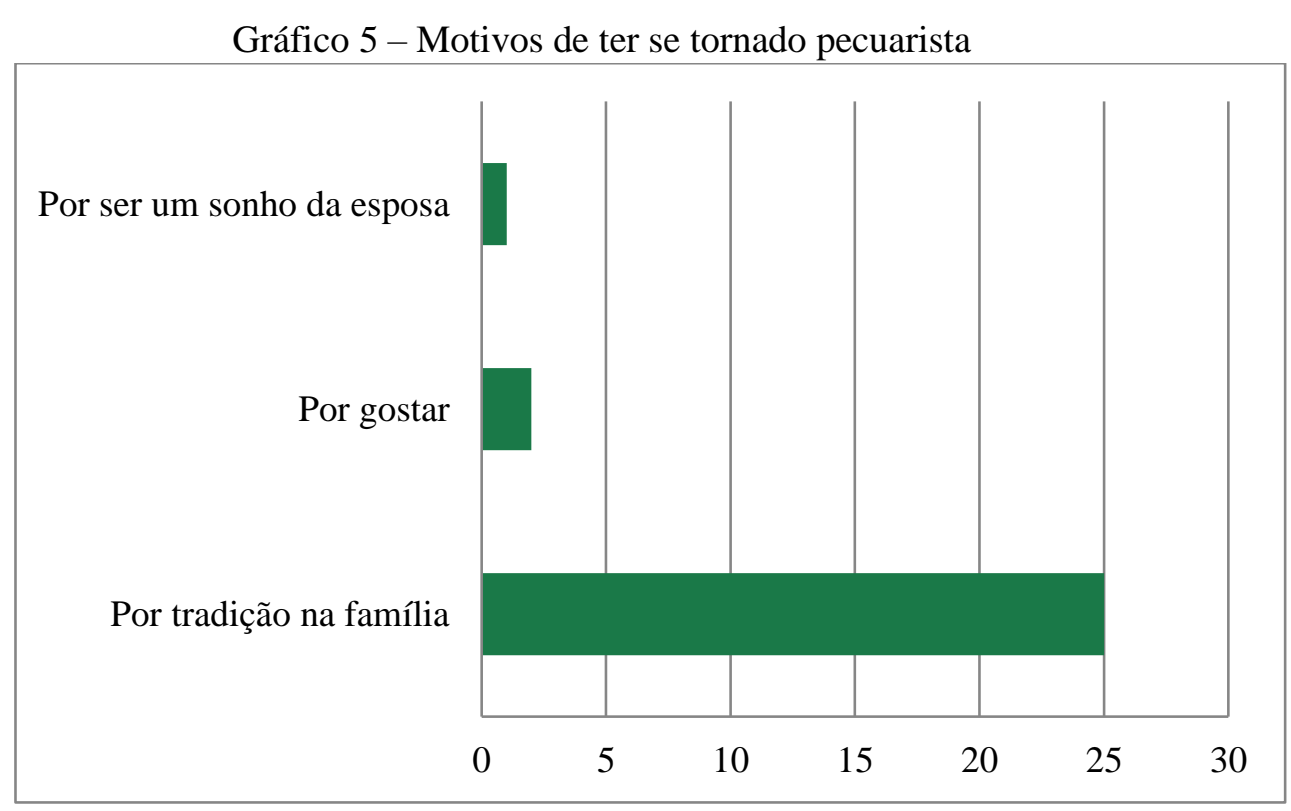

Fonte: A pesquisa (2017)

Eis um dado que permite questionar a ideia de uma escolha direcionada pelo desejo. A grande maioria dos entrevistados escolheu a ocupação por tradição familiar. Esta foi uma resposta padrão.

\section{CONCLUSÃO}

Nos dados relacionados à hipótese 1, a Tabela 1 indica que quase $80 \%$ dos pecuaristas pantaneiros não vivem mais exclusivamente da pecuária, ou seja, desenvolvem outra atividade econômica. Entre aqueles que vivem exclusivamente da pecuária, alguns são aposentados que agora podem se dedicar exclusivamente a ela. Isso mostra que a pecuária não é sua atividade fundamental e essa nova relação com a ocupação tem sido passada para os filhos mais novos e se expressa na situação dos filhos que escolheram outra ocupação, geralmente urbana.

Em relação ao local de residência, 86,20\% residem na cidade de Poconé e o restante em Cuiabá, ou seja, os pecuaristas não moram mais na fazenda. O tamanho bem menor da propriedade, a redução significativa no tamanho do rebanho e os atrativos em termos de aspirações educacionais e ocupacionais oferecidos pela capital, distante 100 quilômetros de Poconé, provavelmente fizeram com que a grande maioria dos filhos dos pecuaristas desistisse 
da vida na fazenda. Temos aqui mudanças na esfera de desejos e oportunidades e os Gráficos 2 e 3 fornecem pistas nesse sentido.

A pecuária pantaneira de 50 anos atrás tinha estrutura familiar de produção. Nessa estrutura, a ajuda dos filhos era fundamental, pois eles posteriormente assumiam a fazenda. $\mathrm{O}$ Gráfico 3 não é conclusivo a este respeito. O conceito de ajuda deve ser mais bem explorado. É necessário entender o que os pais entendem por ajuda.

Nos dados relacionados à hipótese 2, o Gráfico 4 indica que $69 \%$ desenvolve outras atividades econômicas, a maioria ocupações urbanas. O que mostra que o pecuarista pantaneiro se tornou urbano, pois a pecuária não é a atividade econômica principal para $69 \%$. A classificação por faixa etária nos mostra que a maioria tem mais de 50 anos. E, portanto, dificilmente fará investimento em outro status ocupacional.

A Tabela 2 indica que quase $70 \%$ dos pais dos pecuaristas eram pecuaristas. E entre aqueles que os pais não são pecuaristas, alguns a mãe é filha de pecuaristas e herdou a terra. Ou seja, a proporção de pecuaristas pantaneiros que têm em que os pais não eram ligados à pecuária é baixa. Este dado é consistente com o Gráfico 5, motivos de ter se tornado pecuarista, 86,20\% por tradição de família. A atividade econômica pecuarista passava de pai para filho como um status atribuído.

Finalmente dados relativos à escolaridade dos pecuaristas sugere questões para novas investigações. O status de pecuarista é uma ocupação diferente do que a sociologia conceitua como profissão. É possível constatar que 55,17\% dos pecuaristas têm um curso superior, a maioria cursos ligados à área agropecuária, medicina veterinária, zootecnia e agronomia. $\mathrm{Ou}$ seja, o status de pecuarista pode ser desempenhado pelas mais diferentes formações profissionais porque, parece que estruturalmente, ele é compatível com o exercício de outras ocupações. Nesse sentido, o status de pecuarista pantaneiro estaria sofrendo modificações, mas parece estar agora mais próximo da ocupação do pecuarista de terra firme. Essa hipótese merece ser mais bem investigada.

Combinados com dados relacionados à hipótese 1, parece-nos sustentável dizer que os indivíduos escolhem a ocupação de pecuarista pantaneiro como uma atividade econômica complementar. Ou seja, na verdade, ela continua herdada, só que agora terá dos indivíduos o investimento regular de fim de semana. Situação diferente da vivenciada por seus pais e avós, para os quais o status ocupacional de pecuarista pantaneiro era seu status principal e todos os outros gravitavam em torno dele.

Embora a dinâmica da mudança social experimentada pelo status de pecuarista no pantanal de Poconé pareça específica do pantanal, existem algumas características do status ocupacional que parecem ser gerais ao status como um todo. Por exemplo, a condição de ser um status ocupacional não exclusivo. Se no pantanal de Poconé ele era o status ocupacional principal e agora passa a ser secundário, investigações com pecuaristas da área firme do município de Poconé podem ser interessantes para, de uma perspectiva comparativa, entender os dilemas enfrentados pelos pecuaristas quando a pecuária tem condições de ser sua atividade econômica principal. 


\section{REFERÊNCIAS}

BLAU, P.; DUNCAN, O. D. The American Occupational Structure. New York: The Free Press, 1967.

ELSTER, J. Peças e Engrenagens das Ciências Sociais. Rio de Janeiro: Relume-Dumará, 1994.

ELSTER, J. La Explicacion del Comportamiento Social - más tuercas y tornillos para las ciências sociales. Cidade do México: Gedisa Editorial, 2010.

ETZIONI, A. Organizações Complexas. São Paulo: Atlas, 1973.

GORMAN, E. H. SANDEFUR, R. L. "Golden age," Quiescence, and Revival: How the Sociology of Professions Became the Study of Knowledge-Based Work. Work and Occupations. Vol. 38, $\mathrm{N}^{\mathrm{o}}$ 3, 2011.

HECHTER, M.; KANAZAWA, S. Sociological Rational Theory. Annual Review of Sociology. Vol. 23, p. 191-214, 1999.

HOPCROFT, R. L.; WHITMEYER, J. M. A Choice Model of Occupational Status and Fertility. Journal of Mathematical Sociology. Vol. 34. P. 283-300, 2010.

KANAZAWA, S. Comment: why we love our children. American Journal of Sociology. Vol. 106. $N^{\circ}$ 6: 1761-1788, 2001.

KIYOTA, N.; PERONDI, M. A. Sucessão Geracional na Agricultura Familiar: uma questão de renda? O Mundo Rural no Brasil do Século 21: a formação de um novo padrão agrário e agrícola. Editores: Buanain, A. M; Alves, E.; Silveira, J. M. e Navarro, Z. p. 1011-1045. Brasília: Embrapa, 2014.

MARTIN, J. L. Social Structures. Princenton: Princenton University Press, 2009.

SANDERSON, S. The Evolution of Human Sociality. New York: Rowman \& Littlefield Publishers, Inc, 2001.

SIlVA, C. J. da; SILVA, J. A. F. No Ritmo das Águas do Pantanal. São Paulo: NUPAUB/USP, 1995.

TURNER, J. H. Sociologia - conceitos e aplicações. São Paulo: Makron Books, 2000.

VILA da SILVA, J. S.; ABDON, M. M. Delimitação do Pantanal Brasileiro e suas Sub-regiões.

Pesq. Agropec. Bras. Brasília. Vol. 33. Número Especial:1703-11, 1998. 